\title{
Evaluating assessment tools of the quality of clinical ethics consultations: a systematic scoping review from 1992 to 2019
}

Nicholas Yue Shuen Yoon ${ }^{1,2}$, Yun Ting Ong ${ }^{1,2}$, Hong Wei Yap ${ }^{1,3}$, Kuang Teck Tay ${ }^{1,2}$, Elijah Gin Lim², Clarissa Wei Shuen Cheong ${ }^{1,2}$, Wei Qiang Lim ${ }^{1,2}$, Annelissa Mien Chew Chin ${ }^{4}$, Ying Pin Toh ${ }^{5}$, Min Chiam Stephen Mason ${ }^{7}$ and Lalit Kumar Radha Krishna ${ }^{1,2,6,7,8,9,10^{*}}$ (D)

\begin{abstract}
Background: Amidst expanding roles in education and policy making, questions have been raised about the ability of Clinical Ethics Committees (CEC) s to carry out effective ethics consultations (CECons). However recent reviews of CECs suggest that there is no uniformity to CECons and no effective means of assessing the quality of CECons. To address this gap a systematic scoping review of prevailing tools used to assess CECons was performed to foreground and guide the design of a tool to evaluate the quality of CECons.

Methods: Guided by Levac et al's (2010) methodological framework for conducting scoping reviews, the research team performed independent literature reviews of accounts of assessments of CECons published in six databases. The included articles were independently analyzed using content and thematic analysis to enhance the validity of the findings.

Results: Nine thousand sixty-six abstracts were identified, 617 full-text articles were reviewed, 104 articles were analyzed and four themes were identified - the purpose of the CECons evaluation, the various domains assessed, the methods of assessment used and the long-term impact of these evaluations.

Conclusion: This review found prevailing assessments of CECons to be piecemeal due to variable goals, contextual factors and practical limitations. The diversity in domains assessed and tools used foregrounds the lack of minimum standards upheld to ensure baseline efficacy.

To advance a contextually appropriate, culturally sensitive, program specific assessment tool to assess CECons, clear structural and competency guidelines must be established in the curation of CECons programs, to evaluate their true efficacy and maintain clinical, legal and ethical standards.
\end{abstract}

Keywords: Clinical ethics committees, CECs, Clinical ethics consultations, Medical ethics, Clinical ethics

\footnotetext{
* Correspondence: Lalit.Radha-Krishna@liverpool.ac.uk

'Division of Supportive and Palliative Care, National Cancer Centre Singapore, Level 4, 11 Hospital Drive, Singapore 169610, Singapore

${ }^{2}$ Yong Loo Lin School of Medicine, National University of Singapore, 1 E Kent Ridge Road, NUHS Tower Block, Level 11, Singapore 119228, Singapore

Full list of author information is available at the end of the article
}

(C) The Author(s). 2020 Open Access This article is licensed under a Creative Commons Attribution 4.0 International License, which permits use, sharing, adaptation, distribution and reproduction in any medium or format, as long as you give appropriate credit to the original author(s) and the source, provide a link to the Creative Commons licence, and indicate if changes were made. The images or other third party material in this article are included in the article's Creative Commons licence, unless indicated otherwise in a credit line to the material. If material is not included in the article's Creative Commons licence and your intended use is not permitted by statutory regulation or exceeds the permitted use, you will need to obtain permission directly from the copyright holder. To view a copy of this licence, visit http://creativecommons.org/licenses/by/4.0/ The Creative Commons Public Domain Dedication waiver (http://creativecommons.org/publicdomain/zero/1.0/) applies to the data made available in this article, unless otherwise stated in a credit line to the data. 


\section{Introduction}

Facing shifts in sociocultural paradigms, resource pressures and increasing complexities of medical care [1], the role of Clinical Ethics Committees (CEC)s has evolved. Whilst retaining its original role in facilitating "the process and outcomes of patient care by helping to identity, analyze, and resolve" ethical, moral and legal issues in clinical care [2] CECs have come to adopt active roles in education and policy making. To meet these goals, the CEC which is understood to be "[a team of] physicians, social workers, attorneys, and theologians...which serves to review the individual circumstances of ethical dilemma and which has [previously shown to provide] much in the way of assistance and safeguards for patients and their medical caretakers" [3] now educate patients, their families, clinicians, and the host organization as it guides them through the conflicts and uncertainties impacting their specific healthcare situation $[4,5]$. CECs have also engaged in policy making roles to ensure consistency, transparency and accountability in resolving ethical issues in the clinical setting $[3,4]$.

Acknowledging these wider roles that have fuelled the expansion of CECs in North America [6, 7], Asia [8-12] and Europe [13-15], the American Society for Bioethics and Humanities (ASBH) - a key educational organization focused on advancing clinical and academic bioethics in the United States - has proposed a list of Core Competencies for clinical ethics consultants [16]. It is held that meeting these core competencies would allow CEC members to meet their new roles and responsibilities as well as prevailing clinical, ethical, professional and legal standards of practice $[17,18]$. The ASBH's Core Competencies also help set out the compositions of the CECs [19-21], inform the structuring [22-24] and monitoring of the content [5], quality [17, 18] and accountability $[5,25,26]$ of CEC consultations (henceforth CECons) $[19,20,27]$ and offer a means of ensuring the long-term viability of CECs [17, 28, 29].

However despite the establishment of ASBH's Core Competencies, there is little means of assessing the quality of CECons [19, 20, 27].

\section{Need for this review}

Focusing upon determining if and how CECs meet their 'fundamental' role of carrying out CECons and if these consults meet prevailing requirements, a systematic scoping review (SSR) of prevailing tools to assess the quality of CECons is proposed. This narrow area of study sets this SSR apart from previous reviews of CECs that have taken a more generalized view of assessing CEC function [30, 31]. It is hoped that mapping prevailing methods of assessing CECons will guide the design of a robust CECons assessment tool. This need to address this lack of an assessment tool to evaluate the approach, quality and content of CECcons [32], assess its long-term effects on patient care and safety $[6,33]$ and standardise and benchmark practice [34] is further underlined by evidence of variations in CEC practice and CECcons methods that will ultimately undermine the efficacy and standing of CECs as a whole. Better understanding of how CECs meet this key role will also improve oversight and improvements to quality standards and guidelines of CECs $[35,36]$.

\section{Methods}

An SSR of prevailing methods and tools to assess CECons is proposed to map the size and scope of available literature in peer-reviewed and grey literature studies [37-41]. The flexible nature of an SSR enables systematic extraction and synthesis of actionable and applicable information [42] across a wide range of practice settings [43, 44], whilst summarizing available literature on CECons assessments $[45,46]$ and circumnavigating limitations posed by a dearth of relevant literature [43, 44, 47-49]. This data along with the identification of commonalities within CEC practice could lay the foundations for a consistent approach to assessing CECons [37-41].

Levac et al's (2010) [50] adaptation of Arksey and O'Malley's (2005) [37] methodological framework for conducting scoping reviews was adopted to map "the key concepts underpinning a research area and the main sources and types of evidence available" [40] and to "produce a profile of the existing literature in a topic area, creating a rich database of literature that can serve as a foundation" to inform practice and guide further research [38, 51, 52]. Guided by PRISMA-P 2015 checklist [45], a six-stage systematic scoping review protocol was developed for this study [37-41].

\section{Stage 1: identifying the research question}

To better understand prevailing CECons assessment tools, the ten-member research team discussed prevailing concerns regarding evaluations of CECons with a team of experts consisting of two medical librarians, five CEC members at the National Cancer Centre Singapore and Singapore General Hospital; academics from the Centre for BioMedical Ethics at the National University Singapore and the Palliative Care Institute Liverpool at the University of Liverpool; and clinicians and educationalists from the Yong Loo Lin School of Medicine at the National University of Singapore (NUS) and DukeNUS Medical School (henceforth the expert team).

To further focus this review on assessments of CECons, Post et al. (2015)'s description of CECons was adopted to guide this process - areas to consider included "the goals of ethics consultation, who may perform ethics consultation, who may request ethics consultations, what requests are appropriate for the ethics consultation 
service, what requests are appropriate for ethics case consultation, which consultation model(s) may be used and when, who must be notified when an ethics case consultation has been requested, how the confidentiality of participants will be protected, how ethics consultations will be performed, how ethics consultations will be documented, who is accountable for the ethics consultation service and how the quality of ethics consultation will be assessed and assured" ([4], p.144). From this description, it is evident that assessments of the CECons must necessarily include evaluations of personnel and the processes involved in CECons, the methods used to assess CECons and the outcomes of the CECons.

To this end, the expert and research teams determined the primary research question to be "what tools are available to evaluate the quality of CECons?" The secondary research questions include "what domains of CECons were evaluated in prevailing assessment tools, or were proposed to be evaluated?" and "how were they assessed, or proposed to be assessed?"

These questions were designed on the population, concept and context elements of the inclusion and exclusion criteria [53], using a PICOS format (Table 1). The draft protocol was designed and shaped by feedback from the panel of experts and research team.

\section{Stage 2: identifying relevant studies}

Independent pilot searches were carried out by the ten members of the research team using variations of "clinical ethics consultations" and "assessment" that appeared in titles and abstracts of research papers in PubMed between 1st January 1992 and 17th December 2019. The searches were confined to articles published after 1992, in acknowledgment of the year the Joint Commission's first recognized the CEC's role in patient care [4]. The detailed search strategy for PubMed is shown in Table 1 in the Additional file 1. Based on these findings the research team guided by the expert team created the search terms and strategies for the other databases.

The research team adopted the search strategies set out for each database and carried out independent searches of each database. The results of the independent pilot searches were discussed online and at face-to-face meetings where Sambunjak et al. (2010)'s 'negotiated consensual validation' approach was used to achieve consensus on the final list of abstracts to be included [54]. Guided by the expert team, the research team conducted independent searches of PubMed, Embase, JSTOR, ERIC, Scopus and PsycInfo databases between 18th October 2019 to 17th December 2019.

\section{Stage 3: selecting studies to be included}

Each member of the research team independently screened the titles and abstracts using the same screening tool. The list of articles identified by each member of the research team were shared and discussed online and at face-to-face meetings. 'Negotiated consensual validation' approach was employed to achieve consensus on the final list of full text articles to be studied and analyzed.

\section{Stage 4: data characterisation and analysis}

With a focus on evaluating personnel, process and engagement of stakeholders in CECons, three members of the research team adopted Hsieh and Shannon's approach to directed content analysis (2006) to independently assess the included articles $[55,56]$. Four categories were drawn from Adams et al's (2014) [57] review of Single-IRBs, Chenneville's IRB Researcher's Assessment Tool [58] and the core characteristics of CECs highlighted by Post et al. (2015) [4] and Flamm (2012) [59].

Concurrently in keeping with Krishna's 'Split Approach' [60] that was adopted to enhance the trustworthiness and reproducibility of the analysis, three other members of the study team employed Braun and Clarke's (2006) [61] thematic analysis approach to independently analyze the included articles. All articles were analysed through independent use of thematic analysis and directed content analysis. Use of Krishna's 'Split Approach' [60] served as a means of confirming and triangulating the findings [62]. Concurrently, 'negotiated consensual validation' served as a means of peer debrief thus enhancing their validity $[54,63]$.

Table 1 PICOS

\begin{tabular}{lll}
\hline PICOS & Inclusion & Exclusion \\
\hline $\begin{array}{ll}\text { Population } \\
\text { Intervention }\end{array}$ & Stakeholders directly involved within the CECon process & Stakeholders not directly involved within the CECon process \\
Comparison & $\begin{array}{l}\text { Comparison of prevailing methods and domains of } \\
\text { CECon assessment }\end{array}$ & $\begin{array}{l}\text { Description of CECon activities without any relation } \\
\text { to assessment in any way. }\end{array}$ \\
Outcome & $\begin{array}{l}\text { Outcome measures and challenges faced in assessing } \\
\text { CECon practices, curricula and programs }\end{array}$ & \\
Study Design & $\begin{array}{l}\text { Articles formally assessing the quality of CECons as well as } \\
\text { papers that discussed the assessment of the quality of CECons }\end{array}$ & Opinion articles were excluded. \\
& Published between 1st January 1992 and 17th December 2019 & \\
\hline
\end{tabular}


Stage 5: collating, summarizing, and reporting the results Nine thousand sixty-six abstracts were identified, 617 full-text articles were reviewed and 104 full text articles were analyzed. (Fig. 1: PRISMA Flowchart). When compared, the findings of concurrent thematic and content analysis revealed the same themes/categories allowing them to be presented together.

The narrative produced was guided by the Best Evidence Medical Education (BEME) Collaboration guide $[64,65]$ and the STORIES (STructured apprOach to the Reporting In healthcare education of Evidence Synthesis) statement [66]. Critical appraisals were deemed not necessary for this scoping review as it aimed to consider a wide landscape of articles and thus did not seek to exclude articles through critical appraisal scores.

\section{Stage 6: consultation with key stakeholders}

Feedback was sought from key stakeholders after the results were collated and reported.

\section{Results}

The four themes/categories elucidated were the purpose of the CECons evaluation, the various domains assessed, the methods of assessment used and the long-term impact of these evaluations. These are outlined in Fig. 2.

\section{Purpose of CECon evaluation}

The primary reason for evaluating CECons was to certify [67-69] or accredit [9] CEC consultants to ensure that they possessed the 'necessary competencies' [70]. CECons were also assessed to determine their impact on patient care [18, 71-75] and benchmark their programs against prevailing standards [17, 76, 77].

\section{Domains assessed}

Four domains were assessed: the consultant(s), consultation process, decisions made, and support provided.

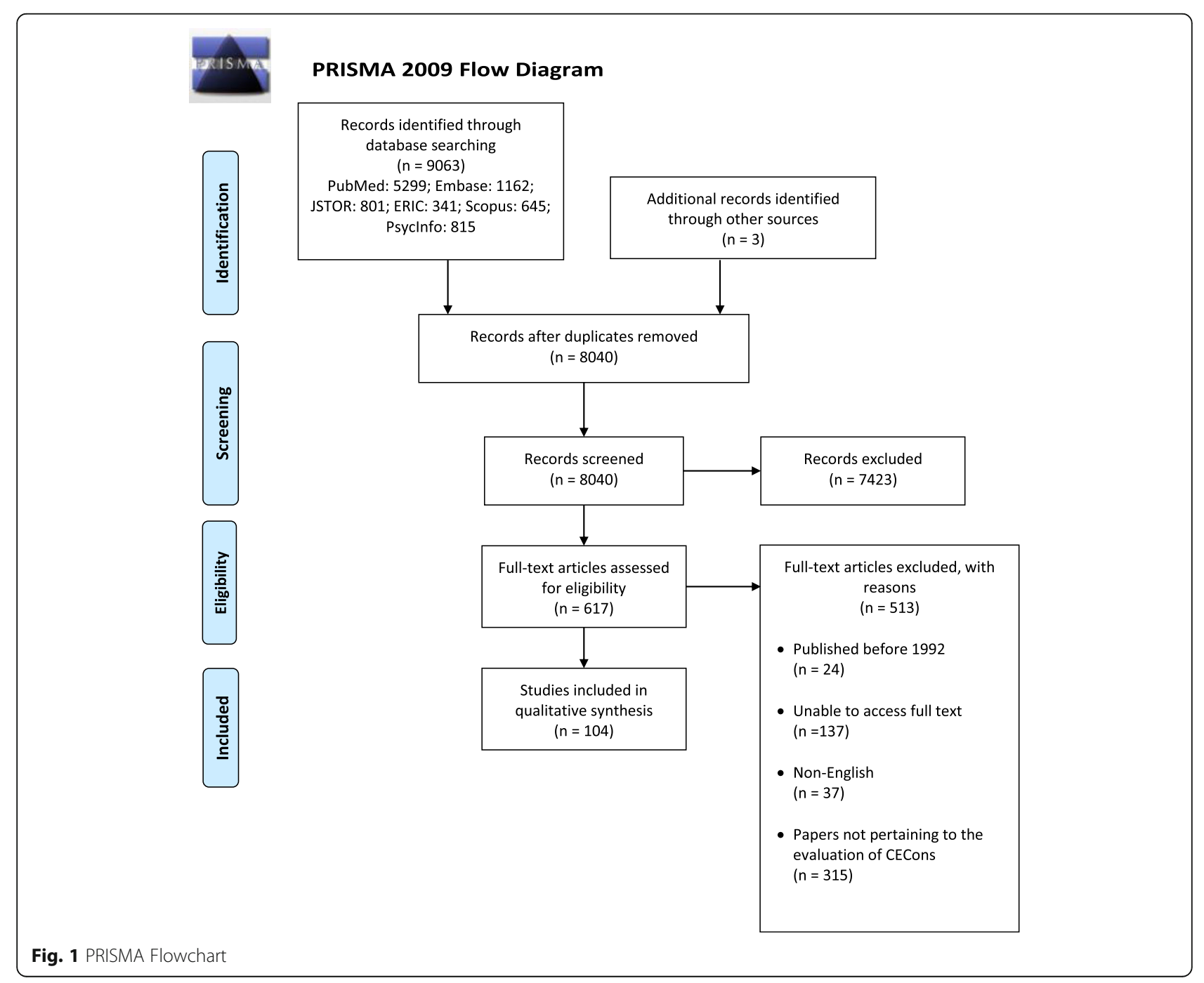




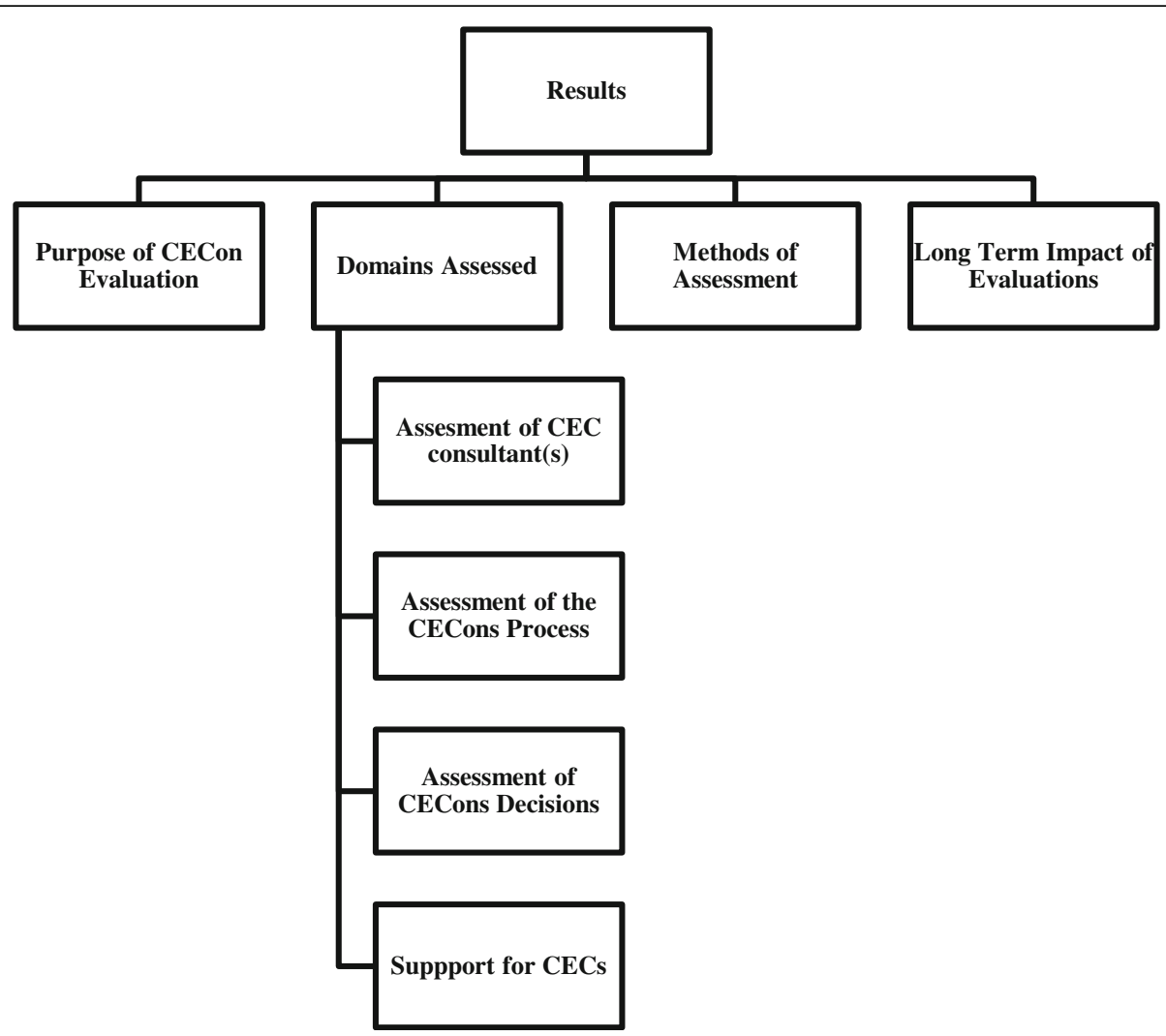

Fig. 2 Results of This Review

\section{i. Assessment of CEC consultant(s)}

The CEC consultant's character, performance and values were seen to influence the perception, process and outcome of CECons. Desired personal attributes included tolerance, patience, compassion, honesty, self-knowledge, courage, prudence, humility, and integrity [70, 78-80]. Professional proficiencies sought after included prior training and experience with CEC practices $[7,16,79,81-$ 86], ethico-legal knowledge [69, 78-81, 83, 86-96] and active involvement in promoting awareness of ethical issues in the clinical environment [80, 91, 92]. An effective CEC consultant also showed interest in organizational ethics [7], educating and guiding others on ethical issues [80, 91, 92] and aligning expectations and practice with institutional and CEC standards $[82,86]$. Some studies evaluated all members of the CECons as a whole [22, 33, 97] and their ability to provide a broad review of ethico-legal and moral considerations [73, 98].

\section{ii. Assessment of the CECons process}

The CECons process was assessed through the approaches they employed such as whether all relevant information had been gathered [5, 14, 99-103] and that all ethical $[5,14,73,79,90,99-106]$ and moral issues $[100,102]$ were considered and analyzed together holistically $[100,102]$ in an objective [103] and accountable manner [107] whilst maintaining confidentiality [15, 79, 90, 103, 108].

Considerations also included if they were timely [31, 79, 109, 110], structured and accessible to all stakeholders $[5,9,31]$. In addition to conflicting or alternative positions taken up during the CECons [5, 14, 99-103], details of the deliberation process and whether consensus was reached on guidance provided were also assessed [100]. The presence of clear communication between consultants, healthcare professionals, patients and their families $[5,77$, $79,91,92,99,111-117]$, the manner in which medical information was interpreted for these stakeholders [79, 111, 112] and if the 'most important information [5]' was effectively articulated to them were also assessed.

Stakeholder satisfaction $[9,30,85,91,116]$, their perceived helpfulness $[74,75,89,91,105,109,114-118]$ and timeliness $[15,88,98,116,119]$ were likewise considered. The levels of stress they experienced during CECons participation $[74,75,91,119]$ and the likelihood that users would recommend the CECs service to others $[15,75,85,89,91,109,112,116,120]$ also served as a marker of their satisfaction. 


\section{iii. Assessment of CECons decisions}

CECons decisions were assessed on whether

a. they were perceived to be effective overall $[5,7$, $111,112,114]$

b. they considered healthcare cost, clinical outcomes and treatment decisions in guidance provided [14, $17,18,73-75,91,121-125]$

c. guidance enhanced the healthcare professionals' ethical competency [31, 71, 72, 91, 118, 123, 124]

d. guidance adhered to organizational standards [71] and regarded as ethically, contextually, socioculturally and practically appropriate $[5,14$, 73, 88, 99-101, 105]

e. they were communicated to various stakeholders involved [5, 31]

f. they were easy to understand by stakeholders, accessible to stakeholders and structured $[5,9]$

g. they successfully influenced patient care provided $[7,74,75,92,99,105,108,112,114,116,117,119-$ 121] through assessment and recommendation of improvements [7, 30, 75, 105, 108]

\section{iv. Support for CECs}

The provision of financial and administrative support $[108,126,127]$ for the CEC was often assessed and seen to impact its ability to provide effective consultations $[88,103,108,126,127]$.

\section{Methods of Assessment}

Assessments were carried out through:

i. Self-appraisals by CEC consultants $[79,82]$

ii. Appraisals by external CEC members not involved in the particular CECons [76, 99, 108, 128, 129]

iii. Feedback from patients and family members [14, $69,74,91,92,114,130,131]$

iv. Input from healthcare professionals $[5,14,15,33$, $72,74,80,85,87,90,91,98,103,111,112,114$, $118,119,127,130]$

v. Evaluations by senior clinicians [82, 84, 93, 102, 104, 127]

vi. Evaluations by administrators or organizational representatives [77]

Assessments methods also include:

i. Longitudinal assessments that take place over many years [72]

ii. Single time point assessments a. focus group interviews $[14,74,76,77,84,87$, $90,92,98,103,127,130]$

b. questionnaires $[33,72,74,79,85,91,92,102$, $111,112,114,119,127]$

iii. Specific appraisal of CECons decisions

a. case report analysis $[5,15,77,93,100,101,104$, $106,108,114,122,128,129,132]$

b. impact of CECons decisions such as via randomized controlled trials where an intervention group who received CECons were compared to a control group who did not $[30,74,75,99,121,122]$

iv. Assessment of CECons' shortcomings [85, 98, 103, 107, 126]

v. Documentation of CEC training and experience by consultants through portfolios and their subsequent review by senior ethics consultants and faculty [16, $82,86]$

Number of referrals made to CEC services, viewed as an endorsement of their effectiveness and reputation [89].

\section{Long-term Impact of CECons Evaluations}

Positive long-term impact of CECons evaluations include the development of new guidelines [15], formalization of ethics consultations [69], and increased self-reflection by CEC consultants [76, 108].

\section{Agreement of results by key stakeholders}

The stakeholders and expert team were in agreement that these findings reflected prevailing practice and called for the design of a new holistic and longitudinal assessment tool for CECons based upon the disparate findings of this review.

\section{Discussion}

In addressing its primary and secondary research questions, this systematic scoping review identifies a variety of tools designed to assess different aspects of CECons. The diversity of these assessment tools stem from the overall goals of assessing CECons which are largely driven by a combination of objectives including accrediting CEC members, evaluating the CECons process and benchmarking it against prevailing standards and/or other programs, and determining their overall outcomes on patient care.

Notably, the four domains assessed were the CEC personnel's attributes and skillsets; the approach employed in the CECons process; the CECons decisions; and the presence of support for the CECs. This explains focus upon. 
(a) the personal and professional attributes of CEC members $[7,16,79,81-86]$ and the composition, training, experience $[70,78-80]$ and skillset of the team $[69,78-81,83,86-96]$ carrying out the CECons (92-94);

(b) the approach adopted and if it considered the ethical, legal, moral, financial, clinical and professional issues holistically and objectively, and whether the process considered prevailing sociocultural and practical issues $[5,14,73,88,99-$ $101,105]$ in a confidential manner $[15,79,90,103$, 108]. Also considered was if the CECons was timely $[31,79,109,110]$, well-documented, structured, accessible $[5,9,31]$, clearly communicated $[5,77,79$, 91, 92, 99, 111-117] to stakeholders and perceived as satisfactory through recommendations to others $[15,75,85,89,91,109,112,116,120]$;

(c) the CECons decisions and if stakeholders found them effective [74, 75, 89, 91, 105, 109, 114-118], situationally appropriate $[5,14,73,88,99-101,105]$ and well-communicated $[5,31]$, if the guidance provided was educational and enhanced their ethical competency $[31,71,72,91,118,123,124]$ and if it improved patient outcomes $[7,30,75,105,108]$ and had long-term effects on their practice [76, 108];

(d) and the adequate provision of financial and administrative support $[108,126,127]$ deemed to bolster the program and impact the CECs capacity to provide effective consultations $[88,103,108,126,127]$.

With tools ranging from self-appraisals to single time point and longitudinal assessments, perhaps just as significant is the diversity in methods and the quality and type of data generated from them. Such variability in these domains and tools used explains the lack of consistency in CECons assessments. Whilst it may be argued that such diversity merely reflect practical limitations [133] or adaptations to sociocultural and clinical factors [134], a minimum standard must be upheld to ensure baseline efficacy. CEC programs must be rigorously structured and core competencies for CEC members consistently adopted. The Healthcare Ethics Consultant-Certified Program (HEC-C) and Core Competencies for Healthcare Ethics Consultation set out by the ASBH would set the tone for such structuring and training [135] and establish minimum data sets to be evaluated as well as guide standardization of methods used to collect the data [128].

However such a standard setting process must be mindful of the prevailing clinical, educational, ethical, legal, sociocultural, financial and contextual factors influencing the CECs as they continue to expand across North America [6, 7], Asia [8-12] and Europe [13-15]. It may prove useful for CECs to adopt a Modified Delphi approach to consider the key elements of an effective CECons process and design an assessment tool that better suits their context, focus, capabilities and capacities [118].Indeed, like pieces of a jigsaw, bringing together and carefully deliberating the disparate considerations and domains discerned by this systematic scoping review would allow for a more cohesive and comprehensive assessment tool to be curated.

\section{Limitations}

There are a number of limitations to this review. Firstly, use of the directed content analysis based on a relatively unique interpretation of the data would have been problematic without the employment of the 'Split Approach'. However, whilst the 'Split Approach' addresses concerns surrounding the validity of using a directed content analysis and addresses researcher reflexivity, this approach remains unproven. Despite this, some of these concerns are assuaged with the use of Braun and Clarke's (2006) [61] approach to thematic analysis, which served as a means of confirming the evidence, a form of triangulation and a method of enhancing the validity of the findings.

Secondly, this review drew conclusions from a small pool of papers which were limited to articles published or translated into the English language, primarily from North America and Europe. This may limit the applicability of the findings in wider healthcare settings.

\section{Conclusion}

In addressing its primary and secondary research questions, this systematic scoping review highlights the variable goals, contextual factors and practical limitations behind the lack of a consistent approach to assessing CECons. In so doing this review also highlights the need for the design of a contextually appropriate, culturally sensitive, program specific assessment tool designed around the key domains identified here to be used not only to evaluate the quality and content of CECons but as a means of informing the training and assessment of CEC members, improving CECons procedures, assessing the efficacy and impact of its CECons and benchmarking its practice with other programs and international standards of practice.

With enhancing patient care at the centre of its processes, CECs should employ prevailing design principles and assessment theories to improve its educational and policy making roles in establishing national standards. Whilst there is still much to be done, and the efficacy of CEC's other roles to be evaluated, we believe this systematic scoping review points the way towards more accountable, effective and user-friendly CECs. We look forward to further discourse on this critical aspect of clinical practice. 


\section{Supplementary information}

Supplementary information accompanies this paper at https://doi.org/10. 1186/s12910-020-00492-4.

Additional file 1. Appendix with PubMed Search Strategy and List of Included Articles.

\section{Abbreviations}

CECs: Clinical Ethics Committees; CECons: Clinical Ethics Consultations

\section{Acknowledgements}

This paper is dedicated to the late Dr. S. Radha Krishna whose advice and insights were critical to conceptualization of this review.

The authors wish to thank Chou Ai Mei at the Yong Loo Lin School of Medicine Library and Wing Ma Junyan at the National Cancer Centre Singapore's medical library for their guidance on the literature search and for aid with locating the various articles needed for this review. The authors would also like to thank the anonymous reviewers whose comments greatly enhanced this manuscript.

\section{Authors' contributions}

NYSY was involved in research design and planning, data collection and processing, data analysis, results synthesis, manuscript writing and review and administrative work for journal submission, YTO was involved in research design and planning, data collection and processing, data analysis, results synthesis, manuscript writing and review and administrative work for journal submission, HWY was involved in research design and planning, data collection and processing, data analysis, results synthesis, manuscript writing and review, KTT was involved in research design and planning, data collection and processing, data analysis, results synthesis, manuscript writing and review, EGL was involved in research design and planning, data collection and processing, data analysis, results synthesis, manuscript writing and review, CWSC was involved in research design and planning, data collection and processing, data analysis, results synthesis, manuscript writing and review, WQL was involved in research design and planning, data collection and processing, data analysis, results synthesis, manuscript writing and review, AMCC was involved in conceptualising and developing the search strategy and formulation of the search methodology, YPT was involved in research design and planning, data collection and processing, data analysis, results synthesis, team management and mentoring, MC was involved in manuscript writing and review, SM was involved in manuscript writing and review, LKRK was involved in research design and planning, data collection and processing, data analysis, results synthesis, manuscript writing and review, team management and mentoring. All authors have read and approved the manuscript.

\section{Funding}

No financial support was received for the research, authorship, and/or publication of this article.

\section{Availability of data and materials}

All data generated or analysed during this study are included in this published article.

\section{Ethics approval and consent to participate}

Not applicable.

\section{Consent for publication}

Not applicable.

\section{Competing interests}

All authors declare that there was no conflict of interest.

\section{Author details}

${ }^{1}$ Division of Supportive and Palliative Care, National Cancer Centre Singapore, Level 4, 11 Hospital Drive, Singapore 169610, Singapore. ${ }^{2}$ Yong Loo Lin School of Medicine, National University of Singapore, 1E Kent Ridge Road, NUHS Tower Block, Level 11, Singapore 119228, Singapore. ${ }^{3}$ Lee Kong Chian School of Medicine, Nanyang Technological University, 59 Nanyang Dr, Experimental Medicine Building, Singapore 636921, Singapore. ${ }^{4}$ Medical
Library, National University of Singapore Libraries, National University of Singapore, Blk MD6, Centre, 14 Medical Dr, \#05-01 for Translational Medicine, Singapore 117599, Singapore. ${ }^{5}$ Department of Family Medicine, National University Health System, 5 Lower Kent Ridge Road, Singapore 119074, Singapore. ${ }^{6}$ Division of Cancer Education, National Cancer Centre Singapore, Level 4, 11 Hospital Drive, Singapore 169610, Singapore. ${ }^{7}$ Palliative Care Institute Liverpool, Academic Palliative \& End of Life Care Centre, University of Liverpool, Liverpool, UK. ${ }^{8}$ Cancer Research Centre, University of Liverpool, 200 London Road, Liverpool L3 9TA, UK. ${ }^{9}$ Centre of Biomedical Ethics, National University of Singapore, Blk MD11, 10 Medical Drive, \#02-03, Singapore 117597, Singapore. ${ }^{10}$ Duke-NUS Medical School, 8 College Road, Singapore 169857, Singapore.

Received: 7 April 2020 Accepted: 19 June 2020

Published online: 01 July 2020

\section{References}

1. Fuscaldo G, Cadwell M, Wallis K, Fry L, Rogers M. Developing clinical ethics support for an Australian health service: a survey of clinician's experiences and views. AJOB Empir Bioeth. 2019;10(1):44-54

2. Fletcher JC, Siegler M. What are the goals of ethics consultation? A consensus statement. J Clin Ethics. 1996;7(2):122-6.

3. Supreme Court of New Jersey. In the matter of Karen Quinlan, an alleged incompetent. 1976 [70 N.J. Section 49. Available from: https://law.justia.com/ cases/new-jersey/supreme-court/1976/70-n-j-10-0.html. Accessed date 28 Mar 2020

4. Post LF, Blustein J. Handbook for health care ethics committees. Baltimore: JHU Press; 2015.

5. Pearlman RA, Foglia MB, Fox E, Cohen JH, Chanko BL, Berkowitz KA. Ethics consultation quality assessment tool: a novel method for assessing the quality of ethics case consultations based on written records. Am J Bioeth. 2016;16(3):3-14

6. Fox E, Myers S, Pearlman RA. Ethics consultation in United States hospitals: a national survey. Am J Bioeth. 2007;7(2):13-25.

7. Gaudine A, Thorne L, LeFort SM, Lamb M. Evolution of hospital clinical ethics committees in Canada. J Med Ethics. 2010;36(3):132-7.

8. Fukuyama M, Asai A, Itai K, Bito S. A report on small team clinical ethics consultation programmes in Japan. J Med Ethics. 2008;34(12):858-62.

9. Enjoo SA, Amini M, Tabei SZ, Mahbudi A, Kavosi Z, Saber M. The main indicators for Iranian hospital ethical accreditation. J Adv Med Educ Prof. 2015;3(3):117-32

10. Chen $Y Y$, Chen YC. Evaluating ethics consultation: randomised controlled trial is not the right tool. J Med Ethics. 2008;34(8):594-7.

11. Chen YY, Chu TS, Kao YH, Tsai PR, Huang TS, Ko WJ. To evaluate the effectiveness of health care ethics consultation based on the goals of health care ethics consultation: a prospective cohort study with randomization. 2014;15(1):1

12. Tsai DFC. The growing interest and practice of clinical ethics in Taiwan- a national survey of clinical ethics committee and the progress of a clinical ethics support program. Int J Urol. 2010;17:A277-A8.

13. Slowther AM, McClimans $L$, Price $C$. Development of clinical ethics services in the UK: a national survey. J Med Ethics. 2012;38(4):210-4

14. Pfäfflin M, Kobert K, Reiter-Theil S. Evaluating clinical ethics consultation: a European perspective. Camb Q Healthc Ethics. 2009:18(4):406-19.

15. Førde R, Pedersen R, Akre V. Clinicians' evaluation of clinical ethics consultations in Norway: a qualitative study. Med Health Care Philos. 2008; 11(1):17-25.

16. Kodish E, Fins JJ, Braddock C III, Cohn F, Dubler NN, Danis M, et al. Quality attestation for clinical ethics consultants: a two-step model from the American Society for Bioethics and Humanities. Hast Cent Rep. 2013;43(5): $26-36$.

17. Williamson L. Empirical assessments of clinical ethics services: implications for clinical ethics committees. Clin Ethics. 2007:2(4):187-92.

18. Schildmann J, Molewijk B, Benaroyo L, Forde R, Neitzke G. Evaluation of clinical ethics support services and its normativity. J Med Ethics. 2013;39(11): $681-5$.

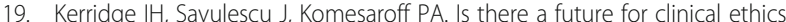
services in Australia? Med J Aust. 2001;175(4):211-3.

20. Fox $\mathrm{E}$ Concepts in evaluation applied to ethics consultation research. J Clin Ethics. 1996;7(2):116-21. 
21. Agich GJ. Why quality is addressed so rarely in clinical ethics consultation. Camb Q Healthc Ethics. 2009;18(4):339-46.

22. Hajibabaee F, Joolaee S, Cheraghi MA, Salari P, Rodney P. Hospital/clinical ethics committees' notion: an overview. J Med Ethics Hist Med. 2016;9:17.

23. Repenshek M. Continuous quality improvement initiatives in ethics: a proposed communication tool. Health Care Ethics USA. 2010;20:2-12.

24. Opel DJ, Wilfond B, Brownstein D, Diekema D, Pearlman R. Characterisation of organisational issues in paediatric clinical ethics consultation: a qualitative study. J Med Ethics. 2009;35(8):477-82.

25. Wynia M. Performance measures for ethics quality; 1999. p. 294-8.

26. Nilson EG, Acres CA, Tamerin NG, Fins JJ. Clinical ethics and the quality initiative: a pilot study for the empirical evaluation of ethics case consultation. Am J Med Qual. 2008;23(5):356-64.

27. Orfali K. Getting the story straight: clinical ethics as a distinctive field. Am J Bioeth. 2018;18(6):62-4.

28. Fox E, Arnold RM. Evaluating outcomes in ethics consultation research. J Clin Ethics. 1996;7(2):127-38.

29. JMC, TM. Evaluating the outcomes of ethics consultation. J Clin Ethics. 2006; 17(2):168-80.

30. Schildmann J, Nadolny S, Haltaufderheide J, Gysels M, Vollmann J, Bausewein CJCDoSR. Ethical case interventions for adult patients. Cochrane Database Syst Rev. 2019(7).

31. Haltaufderheide J, Nadolny S, Gysels M, Bausewein C, Vollmann J, Schildmann JJN. Outcomes of clinical ethics support near the end of life: A systematic review; 2019. p. 0969733019878840

32. Molewijk B, Slowther A, Schildmann J. The European clinical ethics network (ECEN): the professional development of clinical ethics support in Europe and the importance of quality assessment through evaluation research. Bioethica Forum; 2016;9(2):86-89.

33. Magelssen M, Pedersen R, Miljeteig I, Ervik H, Forde R. Importance of systematic deliberation and stakeholder presence: a national study of clinical ethics committees. J Med Ethics. 2019:46(2):66-70.

34. Horner C, Childress A, Fantus S, Malek J. What the HEC-C? An analysis of the healthcare ethics consultant-certified program: one year in. Am J Bioeth 2020;20(3):9-18.

35. Hamel R, Slosar JP, Repenshek M. Answering the call from ASBH's second edition of core competencies in ethics consultation; 2013.

36. Force CCT. Core competencies for healthcare ethics consultation. Glenview: American Society for Bioethics and Humanities; 2011.

37. Arksey H, O'Malley L. Scoping studies: towards a methodological framework. Int J Soc Res Methodol. 2005;8(1):19-32.

38. Grant MJ, Booth A. A typology of reviews: an analysis of 14 review types and associated methodologies. Health Inf Libr J. 2009;26(2):91-108.

39. Lorenzetti DL, Powelson SE. A scoping review of mentoring programs for academic librarians. J Acad Librariansh. 2015;41(2):186-96.

40. Mays N, Roberts E, Popay J. Synthesising research evidence. Studying the organization and delivery of health services: research methods. Edited by: Fulop N, Allen P, Clarke A, Black N. 2001. London: Routledge; 2001.

41. Thomas A, Menon A, Boruff J, Rodriguez AM, Ahmed S. Applications of social constructivist learning theories in knowledge translation for healthcare professionals: a scoping review. Implement Sci. 2014;9(1):54.

42. Du Mont J, Macdonald S, Kosa D, Elliot S, Spencer C, Yaffe M. Development of a comprehensive hospital-based elder abuse intervention: an initial systematic scoping review. PLoS One. 2015;10(5):e0125105.

43. Chidwick P, Faith K, Godkin D, Hardingham L. Clinical education of ethicists: the role of a clinical ethics fellowship. BMC Med Ethics. 2004;5(1):6.

44. Pape D, Manning S, editors. The educational ladder model for ethics committees: confidence and change flourishing through core competency development. HEC forum. 2006;18(4):305-18.

45. Osama T, Brindley D, Majeed A, Murray KA, Shah H, Toumazos M, et al. Teaching the relationship between health and climate change: a systematic scoping review protocol. BMJ Open. 2018;8(5):e020330.

46. O'Donovan J, O'Donovan C, Kuhn I, Sachs SE, Winters N. Ongoing training of community health workers in low-income andmiddle-income countries: a systematic scoping review of the literature. BMJ Open. 2018;8(4):e021467.

47. Pinkus RL, Aumann GM, Kuczewski MG, Medsger A, Meisel A, Parker LS, et al. The Consortium Ethics Program: an approach to establishing a permanent regional ethics network. HEC forum : an interdisciplinary journal on hospitals' ethical and legal issues. Berlin: Springer; 1995.

48. Pinkus RLB, The consortium ethics program: Continuing education for community healthcare professionals. HEC forum. 1999;11(3):233.
49. May T. The breadth of bioethics: Core areas of bioethics education for hospital ethics committees. J Med Philos. 2001;26(1):101-18.

50. Levac D, Colquhoun H, O'Brien KK. Scoping studies: advancing the methodology. Implement Sci. 2010:5:69.

51. Daudt HM, van Mossel C, Scott SJ. Enhancing the scoping study methodology: a large, inter-professional team's experience with Arksey and O'Malley's framework. BMC Med Res Methodol. 2013;13(1):48.

52. Pham MT, Rajić A, Greig JD, Sargeant JM, Papadopoulos A, McEwen SA. A scoping review of scoping reviews: advancing the approach and enhancing the consistency. Res Synth Methods. 2014;5(4):371-85.

53. Peters M, Godfrey C, Mclnerney P, Soares C, Khalil H, Parker D. The Joanna Briggs institute reviewers' manual 2015: methodology for JBI scoping reviews 2015 April 29, 2019. Available from: http://joannabriggs.org/assets/ docs/sumari/Reviewers-Manual_Methodology-for-JBI-Scoping-Reviews_2 015_v1.pdf.

54. Sambunjak D, Straus SE, Marusic A. A systematic review of qualitative research on the meaning and characteristics of mentoring in academic medicine. J Gen Intern Med. 2010;25(1):72-8.

55. Hsieh H-F, Shannon SE. Three approaches to qualitative content analysis. Qual Health Res. 2005;15(9):1277-88.

56. Assarroudi A, Heshmati Nabavi F, Armat MR, Ebadi A, Vaismoradi M. Directed qualitative content analysis: the description and elaboration of its underpinning methods and data analysis process. J Res Nurs. 2018;23(1):4255

57. Adams P, Kaewkungwal J, Limphattharacharoen C, Prakobtham S, Pengsaa K, Khusmith S. Is your ethics committee efficient? Using "IRB metrics" as a self-assessment tool for continuous improvement at the Faculty of Tropical Medicine, Mahidol University, Thailand. PLoS One. 2014;9(11):e113356.

58. Chenneville T, Menezes L, Bylsma LM, Mann A, Kosambiya J, Baxi R. Assessing institutional ethics committees in India using the IRB-RAT. J Empir Res Hum Res Ethics. 2014;9(4):50-9.

59. Flamm AL. Developing effective ethics policy. Guidance for healthcare ethics committees; 2012. p. 131-3.

60. Ng YX, Koh ZYK, Yap HW, Tay KT, Tan XH, Ong YT, et al. Assessing mentoring: a scoping review of mentoring assessment tools in internal medicine between 1990 and 2019. PLoS One. 2020;15(5):e0232511.

61. Braun V, Clarke V. Using thematic analysis in psychology. Qual Res Psychol. 2006;3(2):77-101.

62. Creswell JW, Miller DL. Determining validity in qualitative inquiry. Theory Pract. 2000;39(3):124-30.

63. Sandelowski M, Barroso J. Handbook for synthesizing qualitative research. Berlin: Springer Publishing Company; 2006.

64. Haig A, Dozier M. BEME guide no 3: systematic searching for evidence in medical education--part 1: sources of information. Med Teach. 2003;25(4): 352-63.

65. Haig A, Dozier M. BEME guide no. 3: systematic searching for evidence in medical education--part 2: constructing searches. Med Teach. 2003;25(5): 463-84.

66. Frei E, Stamm M, Buddeberg-Fischer B. Mentoring programs for medical students--a review of the PubMed literature 2000-2008. BMC Med Educ. 2010;10:32.

67. White BD, Jankowski JB, Shelton WN. Structuring a written examination to assess ASBH health care ethics consultation core knowledge competencies. Am J Bioeth. 2014;14(1):5-17.

68. Fox E. The road to certification for clinical ethics consultants: finding our bearings. Am J Bioeth. 2016;16(3):33-5.

69. Tozzo P, Mazzi A, Aprile A, Rodriguez D, Caenazzo L. Certification ISO 9001 in clinical ethics consultation for improving quality and safety in healthcare. Int J Qual Health Care. 2018;30(6):486-91.

70. de Brito GMG, de Oliveira Santa Rosa D. Nurses performance in clinical ethics committees and commissions: an integrative review. Nurs Ethics. 2019;26(3):688-99.

71. de Snoo-Trimp JC, Molewijk B, de Vet HCW. Defining and categorizing outcomes of moral case deliberation (MCD): concept mapping with experienced MCD participants. BMC Med Ethics. 2018;19(1):88.

72. de Snoo-Trimp JC, Molewijk B, Ursin G, Brinchmann BS, Widdershoven GA, de Vet HC, Svantesson M. Field-testing the Euro-MCD Instrument: Experienced outcomes of moral case deliberation. Nurs Ethics; 2020;27(2):390-406.

73. Lobbing T, Carvalho Fernando S, Driessen M, Schulz M, Behrens J, Kobert KKB. Clinical ethics consultations in psychiatric compared to non-psychiatric medical settings: characteristics and outcomes. Heliyon. 2019;5(1):e01192. 
74. Schneiderman LJ, Gilmer T, Teetzel HD. Impact of ethics consultations in the intensive care setting: a randomized, controlled trial. Crit Care Med. 2000; 28(12):3920-4.

75. Schneiderman LJ, Gilmer T, Teetzel HD, Dugan DO, Blustein J, Cranford R, et al. Effect of ethics consultations on nonbeneficial life-sustaining treatments in the intensive care setting: a randomized controlled trial. J Am Med Assoc. 2003;290(9):1166-72.

76. van Baarle EM, Potma MC, van Hoek MEC, Hartman LA, Molewijk BAC, van Gurp JLP. Lessons learned from implementing a responsive quality assessment of clinical ethics support. BMC Med Ethics. 2019;20(1):78

77. Bruce CR, Peña A, Kusin BB, Allen NG, Smith ML, Majumder MA. An embedded model for ethics consultation: characteristics, outcomes, and challenges. AJOB Empir Bioeth. 2014;5(3):8-18.

78. Aulisio MP, Arnold RM, Youngner SJ. Health care ethics consultation: nature, goals, and competencies: a position paper from the society for health and human values-society for bioethics consultation task force on standards for bioethics consultation. Ann Intern Med. 2000;133(1):59-69.

79. Dubler NN, Webber MP, Swiderski DM. Faculty, project tNWGftCEC. Charting the future: credentialing, privileging, quality, and evaluation in clinical ethics consultation. Hast Cent Rep. 2009;39(6):23-33.

80. Delany C, Hall G. 'I just love these sessions'. Should physician satisfaction matter in clinical ethics consultations? Clin Ethics. 2012;7(3):116-21.

81. Leeman CP, Fletcher JC, Spencer EM, Fry-Revere S. Quality control for hospitals' clinical ethics services: proposed standards. Camb Q Healthc Ethics. 1997;6(3):257-68.

82. Picozzi M, Gasparetto A, Nicoli F, Pegoraro R. Certification and evaluation of the clinical ethics consultant. A proposal for Italy. Annali dell'Istituto superiore di sanita. 2018;54(1):61-6.

83. Swiderski DM, Ettinger KM, Webber M, Dubler NN. The clinical ethics credentialing project: Preliminary notes from a pilot project to establish quality measures for ethics consultation. HEC forum. Berlin: Springer; 2010.

84. Berchelmann K, Blechner B. Searching for effectiveness: the functioning of Connecticut clinical ethics committees; 2002.

85. DuVal G, Clarridge B, Gensler G, Danis M. A national survey of US internists experiences with ethical dilemmas and ethics consultation. J Gen Intern Med. 2004;19(3):251-8

86. Fins JJ, Kodish E, Cohn F, Danis M, Derse AR, Dubler NN, et al. A pilot evaluation of portfolios for quality attestation of clinical ethics consultants. Am J Bioeth. 2016;16(3):15-24.

87. Pedersen R, Akre V, Førde R. Barriers and challenges in clinical ethics consultations: the experiences of nine clinical ethics committees. Bioethics. 2009:23(8):460-9.

88. Gaudine A, Lamb M, LeFort SM, Thorne L. Barriers and facilitators to consulting hospital clinical ethics committees. Nurs Ethics. 2011;18(6):76780 .

89. Jansen MA, Schlapbach $L$, Irving $H$. Evaluation of a paediatric clinical ethics service. J Paediatr Child Health. 2018;54(11):1199-205.

90. Scherer A, Alt-Epping B, Nauck F, Marx G. Team members perspectives on conflicts in clinical ethics committees. Nurs Ethics. 2019;26(7-8):2098-112.

91. Yen BM, Schneiderman LJ. Impact of pediatric ethics consultations on patients, families, social workers, and physicians. J Perinatol. 1999;19(5):373.

92. Orr RD, Morton KR, de Leon DM, Fals JC. Evaluation of an ethics consultation service: patient and family perspective. Am J Med. 1996;101(2): 135-41

93. Wasson K, Parsi K, McCarthy M, Siddall VJ, Kuczewski M. Developing an evaluation tool for assessing clinical ethics consultation skills in simulation based education: The ACES project. HEC forum; 2016;28(2):103-13.

94. Agich GJ. The question of method in ethics consultation. Am J Bioeth. 2001 1(4):31-41.

95. Fiester A. The "quality attestation" process and the risk of the false positive. Hast Cent Rep. 2014;44(3):19-22.

96. Chan B, editor Towards Substantive Standardization: Ethical Rules as Ethical Presumptions. HEC forum; 2016: Springer.

97. Meraji M, Sadoughi F, Ghorbani NR, Nezami A. The performance of the ethics committees in teaching hospitals affiliated with Mashhad University of Medical Sciences. Iran Red Crescent Med J. 2014;16(4):e12332.

98. Bahus MK, Førde R. Discussing end-of-life decisions in a clinical ethics committee: an interview study of Norwegian doctors' experience. HEC forum; 2016;28(3):261-72

99. Førde $\mathrm{R}$, Pedersen R. Evaluation of case consultations in clinical ethics committees. Clin Ethics. 2012;7(1):45-50.
100. Beltran JE Ethics committee networks: Facing the future. HEC Forum; 1995; 7(6):353-63.

101. Dubler NN. The art of the chart note in clinical ethics consultation and bioethics mediation: conveying information that can be understood and evaluated. J Clin Ethics. 2013;24(2):148-55.

102. Flicker LS, Rose SL, Eves MM, Flamm AL, Sanghani R, Smith ML. Developing and testing a checklist to enhance quality in ethics consultation. J Clin Ethics. 2014;25(4):281.

103. Dekeuwer C, Bogaert B, Eggert N, Harpet C, Romero M. Falling on deaf ears: a qualitative study on clinical ethical committees in France. Med Health Care Philos. 2019;22(4):515-29.

104. Bruce CR, Bibler TM. Not there yet: evaluating clinical ethics consultation in an accountability culture. Am J Bioeth. 2016;16(3):46-8.

105. Au SS, Couillard P, Roze Des Ordons A, Fiest KM, Lorenzetti DL, Jette N. Outcomes of ethics consultations in adult ICUs: a systematic review and meta-analysis. Crit Care Med. 2018;46(5):799-808.

106. Sanelli-Russo S, Folkers KM, Sakolsky W, Fins JJ, Dubler NN. Meaningful use of electronic health records for quality assessment and review of clinical ethics consultation. J Clin Ethics. 2018;29(1):52-61.

107. Arzuaga BH. Development of a clinical ethics committee De Novo at a small community hospital by addressing needs and potential barriers. J Clin Ethics. 2017;28(2):153-8.

108. Pedersen R, Hurst S, Schildmann J, Schuster S, Molewijk B. The development of a descriptive evaluation tool for clinical ethics case consultations. Clin Ethics. 2010;5(3):136-41.

109. La Puma J, Stocking CB, Darling CM, Siegler M. Community hospital ethics consultation: evaluation and comparison with a university hospital service. Am J Med. 1992:92(4):346-51.

110. Berkowitz KA, Katz AL, Powderly KE, Spike JP. Quality assessment of the ethics consultation service at the organizational level: accrediting ethics consultation services; 2016

111. Bartlett VL, Finder SG. Lessons learned from nurses' requests for ethics consultation: why did they call and what did they value? Nurs Ethics. 2016; 25(5):601-17.

112. Finder SG, Bartlett VL. Discovering what matters: interrogating clinician responses to ethics consultation. Bioethics. 2017;31(4):267-76.

113. Kadioğlu FG, Can R, Okuyaz S, Yalçin SO, Kadioğlu NS. Physicians' attitudes toward clinical ethics consultation: a research study from Turkey. Turk J Med Sci. 2011;41(6):1081-90.

114. McClung JA, Kamer RS, DeLuca M, Barber HJ. Evaluation of a medical ethics consultation service: opinions of patients and health care providers. Am J Med. 1996;100(4):456-60.

115. Morrison W, Womer J, Nathanson P, Kersun L, Hester DM, Walsh C, et al. Pediatricians' experience with clinical ethics consultation: a national survey. I Pediatr. 2015;167(4):919-24.e1.

116. White JC, Dunn PM, Homer L. A practical instrument to evaluate ethics consultations. HEC Forum. 1997:9(3):228-46.

117. Volpe R. Ongoing evaluation of clinical ethics consultations as a form of continuous quality improvement. J Clin Ethics. 2017:28(4):314-7 http://www. clinicalethics.com.libproxy1.nus.edu.sg/single_article/chianoa1wIA.html.

118. Svantesson M, Karlsson J, Boitte P, Schildman J, Dauwerse L, Widdershoven $\mathrm{G}$, et al. Outcomes of moral case deliberation-the development of an evaluation instrument for clinical ethics support (the Euro-MCD). BMC Med Ethics. 2014;15(1):30

119. Gacki-Smith J, Gordon EJ. Residents' access to ethics consultations: knowledge, use, and perceptions. Acad Med. 2005;80(2):168-75.

120. Orr RD, Moon E. Effectiveness of an ethics consultation service. J Fam Prac 1993;36(1):49-53.

121. Chen Y-Y, Chu T-S, Kao Y-H, Tsai P-R, Huang T-S, Ko W-J. To evaluate the effectiveness of health care ethics consultation based on the goals of health care ethics consultation: a prospective cohort study with randomization. BMC Med Ethics. 2014:15(1):1.

122. Batten J. Assessing clinical ethics consultation: processes and outcomes Med L. 2013:32:141.

123. Schildmann J, Nadolny S, Haltaufderheide J, Gysels M, Vollmann J, Bausewein C. Do we understand the intervention? What complex intervention research can teach us for the evaluation of clinical ethics support services (CESS). BMC Med Ethics. 2019;20(1):48.

124. Swetz KM, Hook CC, Henriksen Hellyer JM, Mueller PS. Health care ethics consultation competences and standards: a roadmap still needing a compass. Am J Bioeth. 2013;13(2):20-2. 
125. Mills $A E$, Tereskerz $P$, Davis W. Is evaluating ethics consultation on the basis of cost a good idea? Camb Q Healthc Ethics. 2005;14(1):57-64.

126. Schochow M, Schnell D, Steger F. Implementation of clinical ethics consultation in German hospitals. Sci Eng Ethics. 2019;25(4):985-91.

127. Slowther A, Bunch C, Woolnough B, Hope T. Clinical ethics support services in the UK: an investigation of the current provision of ethics support to health professionals in the UK. J Med Ethics. 2001;27(suppl 1):i2-8.

128. Reiter-Theil S, Schurmann J. Evaluating clinical ethics support: on what grounds do we make judgments about reports of ethics consultation? In: Finder SG, Bliton MJ, editors. Peer review, peer education, and modeling in the practice of clinical ethics consultation: The Zadeh Project. Cham: Springer Copyright 2018, The Author(s); 2018. p. 165-78.

129. Smith ML, Bisanz AK, Kempfer AJ, Adams B, Candelari TG, Blackburn RK. Criteria for determining the appropriate method for an ethics consultation. Hec Forum; 2004:16(2):95-113.

130. Schneiderman LJ, Gilmer T, Teetzel HD, Dugan DO, Goodman-Crews P, Cohn F. Dissatisfaction with ethics consultations: the Anna Karenina principle. Camb Q Healthc Ethics. 2006;15(1):101-6.

131. Førde R, Linja T. "It scares me to know that we might not have been there!": a qualitative study into the experiences of parents of seriously ill children participating in ethical case discussions. BMC Med Ethics. 2015;16(1):40.

132. Geppert C, Chanko BL. The CASES approach to ethics consultation: the centrality of the ethics question. Am J Bioeth. 2016;16(2):80-2.

133. Shuman AG, Montas SM, Barnosky AR, Smith LB, Fins JJ, McCabe MS. Clinical ethics consultation in oncology. J Oncol Pract. 2013;9(5):240-5.

134. Perkins HS. Culture as a useful conceptual tool in clinical ethics consultation. Camb Q Healthc Ethics. 2008;17(2):164-72.

135. Siegler M. The ASBH approach to certify clinical ethics consultants is both premature and inadequate. J Clin Ethics. 2019;30(2):109-16.

\section{Publisher's Note}

Springer Nature remains neutral with regard to jurisdictional claims in published maps and institutional affiliations.

Ready to submit your research? Choose BMC and benefit from:

- fast, convenient online submission

- thorough peer review by experienced researchers in your field

- rapid publication on acceptance

- support for research data, including large and complex data types

- gold Open Access which fosters wider collaboration and increased citations

- maximum visibility for your research: over $100 \mathrm{M}$ website views per year

At $\mathrm{BMC}$, research is always in progress.

Learn more biomedcentral.com/submissions 